ISBN 978-93-84468-83-5

International Conference on Studies in Arts, Law and Education

(ICALE-2016)

Singapore Dec. 5-6, 2016

\title{
Work Performance Efficiency Development of Personnel at O.Y.T. Co., Ltd.
}

\author{
Vichit Tantipongpiradech, and Dr. Vatchara Yeesuntes \\ watchara.yee@kbu.ac.th \\ Post graduate school of business administration \\ Kasembundit university,Bangkok
}

\begin{abstract}
The purpose of the study is to determine factors of motivation affecting performance efficiency of employees at O.T.Y. Co., Ltd. The samplings were 187 employees of O.T.Y. Co., Ltd. by using quantitative analysis for the study, rating scale, check list as a questionnaire. Statistic applications for data analysis was percentage, mean, standard deviation, one-way Anova, and regression analysis. Findings from the study indicated that most of respondents were males, age 31-35 years old, operational level position, bachelor degree graduated, average monthly income 15,000=20,000 baht, and work for the company for period of 2-5 years. The overall picture of the opinions of factors of efficiency performance motivation of employees at O.T.Y. Co., Ltd. were at high level consisting of job completion aspect, team work with well-coordinated, proud with job completion, supervisors resolved problems when it arises, assigned job according to skill level, recognition from supervisors and coworkers, trusted by coworkers and supervisors, satisfy with assistant from coworkers, job assigned with skill level, job responsibility, and career advancement, etc. The results from hypothesis testing revealed that personal different, such as gender, age, occupation, level of education, average income, and period of work for the company were not affected the work performance efficiency of employees at O.T.Y. Co., Ltd. and factors of job completion, team work, job recognition by coworkers, job description, presently work satisfactionCorrelated to work performance efficiency at significant level 0.05. Recommendations from the study were that administrative officers should manage on job completion aspect, such as team work, job recognition, and assign job to match the skill level.
\end{abstract}

Keywords---- Work, Personnel, O.Y.T. Co., Ltd

\section{Introduction}

Nowadays rapid change of society, economy, and technology result in a highly competitive business. All organizations or business sectors will need to create competitive advantages with products or services that build customer satisfaction, such as low cost, products quality, and delivery on schedules which happen with continuous efforts and cooperation of employees, including the creation of spirit to work with employees continuously. As for reasons mentioned above, O.Y.T. Co., Ltd. is necessary to strengthen the competitive advantages by increasing the efficiency of human resources management, such as skill development, adjust benefit plan, welfare, compensation, including labor relations in order to make the organization successful as parent company's policy which located in Japan. One of important thing, to motivate the human resources comes from employee commitment to organization, binding, dedication, and honesty which is very important and 
necessary for every organization must try to maintain. One of other thing, the company believes is all employees in comparison to gold that has tremendous value.

For this reason, it become a policy of the company that all employees are trained to understand company policy, love, and commitment in the journey with organization direction, including loyalty toward the organization.

In summary, the human resources administration which is considered as an important resource that makes a successful organization, it must have a method or theory of knowledge that must be used for the development, including improvements in order to overcome the crisis, including the career advancement of staff in all level and positions as well.

From the above information, researcher are interested in studying work performance efficiency development of personnel at O.Y.T. Co., Ltd., and bring the results of the study use as incentive to promote the work efficiency in the operation of O.Y.T. Co., Ltd.

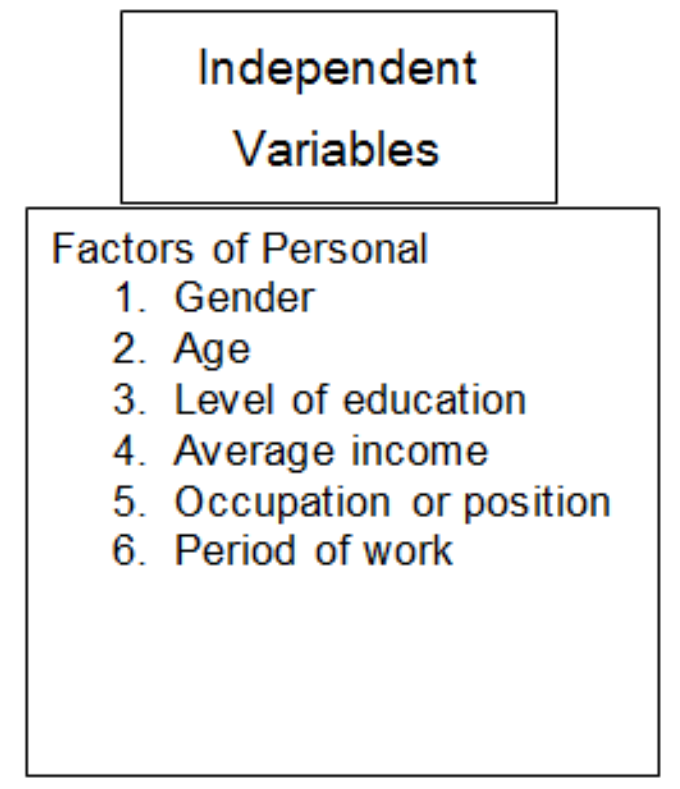

\section{Dependent Variables}

Factors of work motivation performance efficiency of employees

1. Job completion aspect

2. Job recognition aspect

3. Job description aspect

4. Job responsibility aspect

5. Career advancement aspect

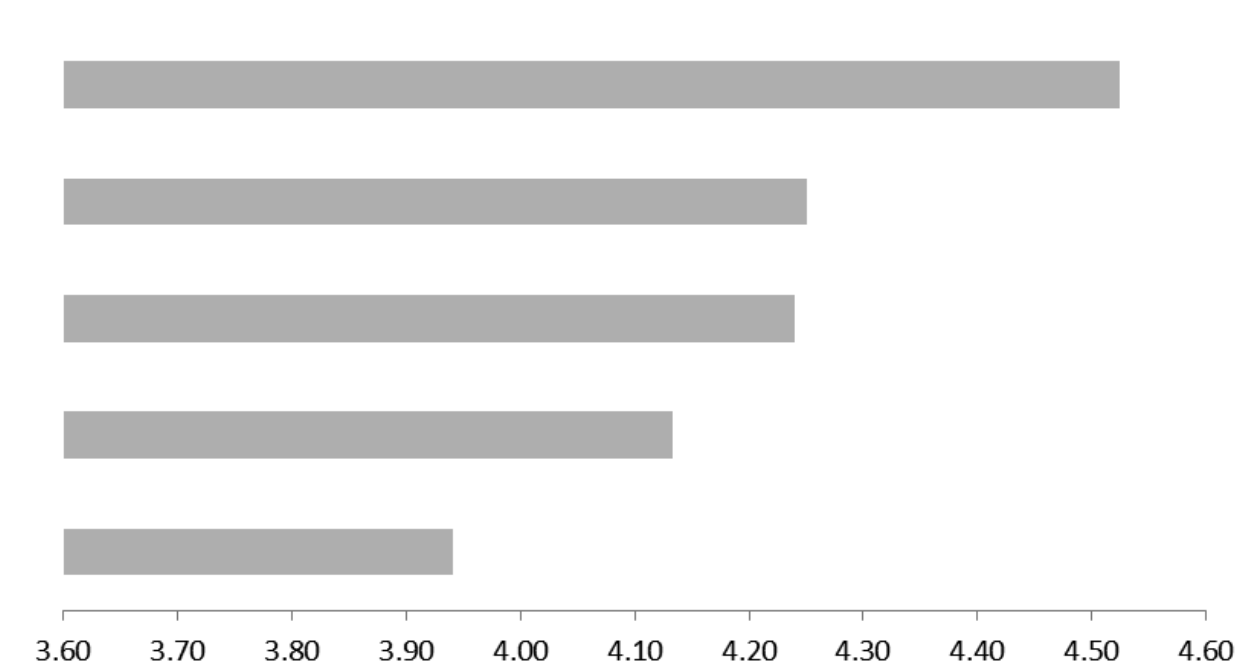

Fig. 1 The results of analysis the overall picture of the important opinions of work performance motivation factors of employees at O.Y.T. Co., Ltd. 
From figure 1: shows the overall picture of the important opinions of work performance motivation factors of employees at O.Y.T. Co., Ltd. were in high level ( $\bar{x}=4.11)$, consisting of career advancement aspect $(\bar{x}=4.22)$, job description aspect $(\bar{x}=4.08)$, jog recognition aspect $(\bar{x}=4.07)$, and job responsibility $(\bar{x}=3.95)$, respectively.

\section{The Results from Hypothesis Testing}

Hypothesis 1.1: Factors of personal different, such as gender affected the work performance efficiency of employee at O.Y.T. Co., Ltd.

The statistical application for the test of hypothesis were independent t-test at level of significant 95 percent. Therefore, the acceptance of $\mathrm{H} 0$ when significant level is greater than 0.05 and the acceptance of $\mathrm{H} 1$ when significant level is less than 0.05 .

TABLE I shows the comparison of work performance efficiency of O.Y.T. employees classified by gender.

\begin{tabular}{|l|c|c|c|c|c|c|}
\hline \multicolumn{1}{|c|}{ Factor of gender } & $\mathrm{N}$ & Mean & $\mathrm{t}$ & $\mathrm{df}$ & Sig. (2-tailed) & results \\
\hline Male & 108 & 3.86 & 1.808 & 185 & .072 & No different \\
\hline Female & 79 & 4.05 & & & & \\
\hline
\end{tabular}

*Significant level 0.05

From table 1: the test of hypothesis with t-test at significant level 0.05 revealed that factors of personal different, such as gender with significant level 0.072 which is greater than significant level 0.05 which accepted hypothesis $\mathrm{H} 0$ means personal different, such as gender of employees were not affected the work performance efficiency of employee at O.Y.T. Co., Ltd.

Hypothesis 1.2: Factors of personal different, such as age affected the work performance efficiency of employee at O.Y.T. Co., Ltd.

The statistical application for the test of the different between the averages of population greater than 2 groups by using one-way Anova at level of significant 95 percent. Therefore, the acceptance of $\mathrm{H} 0$ when significant level (2-tailed) is greater than 0.05 and the acceptance of $\mathrm{H} 1$ when significant level (2-tailed) is less than 0.05 .

TABLE II shows the test of hypothesis of the variance of factors of personal influencing work performance efficiency of O.Y.T. employees classified by age.

\begin{tabular}{|c|c|c|c|c|c|c|}
\hline Factor of age & Sum of square & $\mathrm{df}$ & Mean square & $\mathrm{F}$ & Sig. & results \\
\hline Between group & 3.128 & 4 & .782 & 1.560 & .187 & No different \\
\hline Within group & 91.225 & 182 & .501 & & & \\
\hline Total & 94.353 & 186 & & & & \\
\hline
\end{tabular}

*Significant level 0.05

From table 2: the test of hypothesis with one-way Anova at significant level 0.05 revealed that factors of personal different, such as age with significant level 0.187 which is greater than significant level 0.05 which accepted hypothesis H0 means personal different, such as age of employees were not affected the work performance efficiency of employee at O.Y.T. Co., Ltd.

\section{Summary of the Study}

1. The personal different affected work performance efficiency of the employees.

The test of hypothesis of one-way Anova revealed that the personal different, such gender, age, positions, level of education, average monthly income, and period of work were not affected work performance efficiency of the employees.

2. Factors of work performance motivation correlated to work performance efficiency. 
The test of hypothesis of regression revealed that work completion, team work satisfaction, job recognition, satisfied with assistant from coworkers, job description correlated to work performance efficiency of employees at O.Y.T. Co., Ltd. at significant level 0.05 .

\section{Discussion of the Study Results}

The study of work performance efficiency development of personnel at O.Y.T. Co., Ltd. the researcher have topics for discussions.

From factors affecting work performance efficiency of employees at O.Y.T. Co., Ltd.

Work completion aspect: the overall picture of the opinions of work performance efficiency of employees, such as work completion aspect at O.Y.T. Co., Ltd. were in high level which supported by Gannika Petchsongsri. (2556 B.E.).

Work recognition aspect: the overall picture of the opinions of work performance efficiency of employees, such as work recognition aspect at O.Y.T. Co., Ltd. were in high level which supported by Pavornrat Lertsuwansari. (2555 B.E.).

\section{Recommendations from the Study}

From the study of work performance efficiency development of personnel at O.Y.T. Co., Ltd. the researcher have recommendations as follows: Administrative officers should assign work according to company policy, allowed employees to express the opinions regarding of work related, assign job which appropriate to their skill level, and opportunity for career advancement.

\section{Suggestions for future study}

1. The study of work performance efficiency development of personnel at O.Y.T. Co., Ltd. by using quantitative study with questionnaire and data analysis without in-depth information. Therefore, future research should go into in-depth interview to provide more comprehensive results.

2. For this study, researcher selected a specific respondents group, therefore, the future study should change the demographic for the study and result will benefit for O.Y.T. Co., Ltd.

\section{References}

[1] Kittipong Siriporn. (2551 B.E.). Factors of work performance motivation of operational workers: Case study, Automobile factory, Samut Pragarn province. Thesis. Master of Business Administration. Sripatum University, Cholburi campus.

[2] Jitrawan Thavornvongsakul. (2554 B.E.). The study of paradigm of management influencing work performance efficiency of personnel 2-7 level of Provincial Electricity Authority Head Quarter. Thesis. Silpakon University.

[3] Pansa Kadipisan. (2553 B.E.). Team work efficiency of employees at World plass Co., Ltd., \& Associate. Thesis. Ramkhamhaeng University.

[4] Pravet Maharatsakul. (2553 B.E.). The strategy of knowledge management: Organization development: For quality management. Year $17^{\text {th }}$, issues 154. (August, 2553 B.E.)

[5] Vipada Cooptanont. (2551 B.E.). The organizational behavior and management. Bangkok. So. Jaroen Karnpim printing.

[6] Vararat Keawpiri. (2553 B.E.). Management knowledge. $1^{\text {st }}$ edition, Bangkok: Rajabhat Thonburi University.

[7] Sekson Orakul. (2557 B.E.). Factors of work performance efficiency motivation of employees at Mattle Com Co., Ltd. Thesis. Master of Business Administration. Sripatum University, Cholburi campus.

[8] Sakorn Suksrivong. (2553 B.E.). The management. $6^{\text {th }}$ edition. Bangkok: G.P. Cyber print.

[9] Sutham Phongsamran. (2555 B.E.). Organization behavior. Graduate School. Kasem Bundit University.

[10] Suraphon Petchgrai. (2554 B.E.). Motivation Techniques. Bangkok: Tienwatana Printing.

[11] Pavornrat Lertsuwansari. (2555 B.E.). Work performance satisfaction of personnel at Ratchapruk University. 